\title{
A processing center for using digital hybrid technologies
}

\author{
Dmitry Masailo ${ }^{1 *}$, Alexey Orlov ${ }^{1}$, Vadim Sufiyarov ${ }^{1}$, and Andrey Volkov ${ }^{1}$ \\ ${ }^{1}$ National Technological Initiatives Center "New Industrial Technologies" of Peter the Great St. \\ Petersburg Polytechnic University", 195251, Polytechnicheskaya st., 29, Russian Federation
}

\begin{abstract}
The role of additive technologies in industrial development was highlighted, in particular, for implementation of the concept "Industry 4.0". We discussed their significance for digital manufacturing of parts having complex configuration with internal cavities and functionally gradient properties. We analyzed the main drawbacks of additive technologies and suggested the ways to overcome them. We described the problem in creating the equipment for hybrid technologies on the basis of a processing center and an industrial robot. We developed a concept for creating a Russian-made machine-tool for using hybrid technologies. Solutions are proposed for improving the structure of the material of parts.
\end{abstract}

At the present moment, digital technologies for the parts manufacturing cycle are being quickly developed in the leading industrial countries. First of all, this regards manufacturing billets or articles made of metallic materials. Traditionally, mechanical processing is used that are named "deducing technologies". Among new world trends, there is "additive manufacturing" [1] that makes it possible to manufacture articles having complex geometry that cannot always be made using the traditional processing technologies of cutting, die molding, casting etc. [2, 3] In the concept of transition to "Industry 4.0", this new method of manufacturing is undoubtedly promising. Besides that, additive technologies have the following important advantages: firstly, manufacturing complex-geometry articles with internal cavities, including completely closed cavities; secondly, the possibility to obtain functionally gradient properties of the material the article is made of. However, additive technologies also have some significant drawbacks: firstly, at the moment and, possibly, in the foreseeable future, using the technology of laser melting of powder, wire or tape with focused laser radiation does not allow obtaining the geometry accuracy better than 100 micron and roughness of the surface better than $\mathrm{Rz} 20$; secondly, as using additive technologies implies a metallurgic process, the structure of the material is still not sufficiently predictable, with large internal stresses and defects.

Currently, hybrid technologies for manufacturing metallic parts are widely used, with a combination of additive technologies and traditional mechanical processing.

The pioneer of this development is the German company DMG MORY that manufactured a processing center with an integrated module for powder weld deposition in 2015 (Fig. 1) [4].

\footnotetext{
*Corresponding author: dmasaylo@gmail.com
} 


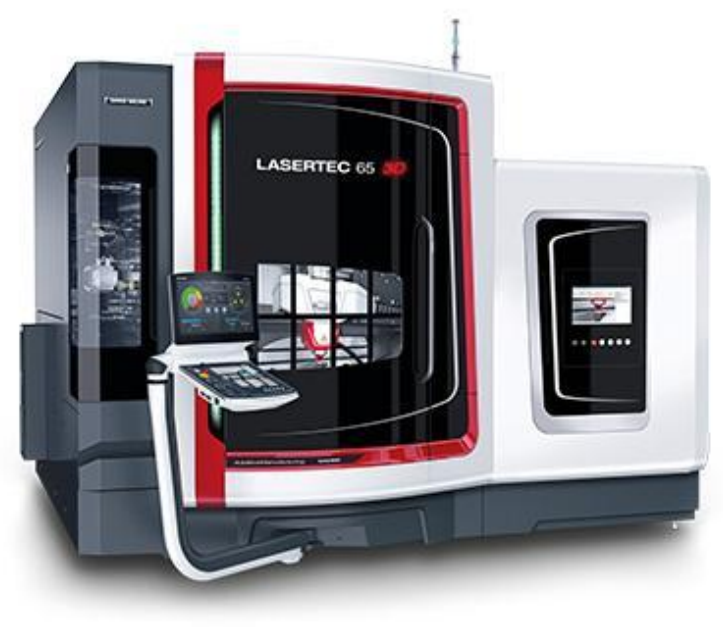

Fig. 1. A hybrid installation DMG MORI LASERTEC 65 3D.

Such approach, with alternating use of different methods of processing in the same working place (weld deposition and mechanical processing) makes it possible to manufacture complex-configuration parts with accurate size and geometry, as well as with good quality of surfaces. However, this solution has rather significant drawbacks of its own. Firstly, the process of direct build-up is carried out in the main working position of the processing center with the use of precision drives of the machine-tool (the feeding mechanism with the tolerance up to several microns is used for build-up of elements with the tolerance of hundreds of microns), and high hardness, which is not very feasible, from the technical point of view. Secondly, in the operating zone of precision drives of the machine-tool, up to ten or more $\mathrm{kW}$ of thermal power is emitted, which definitely causes a significant decrease in the total life cycle of the machine-tool modules due to overheating. Thirdly, the process of the part build-up by direct depositing is accompanied by diffusion of thin powder in the operating zone, with its highly abrasive properties, which also shortens the life cycle of the machinetool. Fourthly, with small-series manufacturing, it is not possible to use experiments to thoroughly adjust the technological process for each part, so significant internal stresses can form, which may cause defects and cracks (usually, stresses are detected in laboratory conditions and relieved by the corresponding thermal processing).

Analysis of the above-listed problems makes it possible to suggest the following scientific-technical measures to improve the efficiency of hybrid technologies. For example, to improve the efficiency of using precision drives of the processing center for hybrid technologies, we suggest introducing an additional working position with a turntable of the normal accuracy, a system for repositioning a part installed on a satellite from one position to the other and back, as well as a technological robot-manipulator of the normal accuracy equipped with a laser head for powder, wire or tape weld deposition. A dedicated zone for 3D depositing makes it possible to separate the zone of mechanic processing so as to eliminate the negative influence of the powder and high temperatures on the mechanisms and units of mechanic processing modules. In order to prevent defects, cracks and unacceptable stresses, it is necessary to install the means to monitor stresses, such as an X-ray diffractometer or an ultra-sound device in the additive module. Additionally, this module can be equipped with inductive heaters with changeable inductors for thermal processing of the most responsible elements of the manufactured article. 
In order to enable selective influence on the structure of the material of the manufactured part, the technological complex can be equipped with a vibrational module for transmitting oscillations to the zone of metal melting, which will have the required effect on the process of crystallization [5-7].

Fig. 2 shows the structure of samples obtained by weld deposition with and without vibrations in the zone of crystallization, where Fig. 2 a shows the case without using vibration, and $2 \mathrm{~b}$ shows the case with using $400 \mathrm{~Hz}$ vibration in the zone of melting and crystallization.

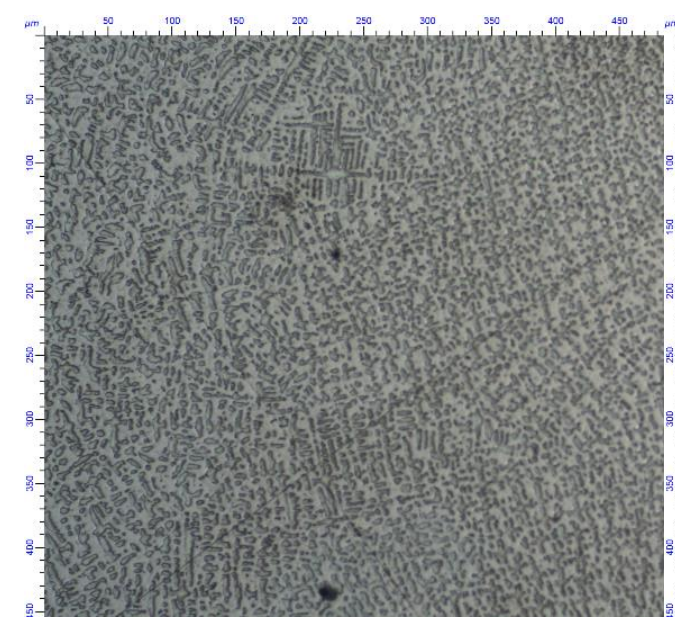

a)

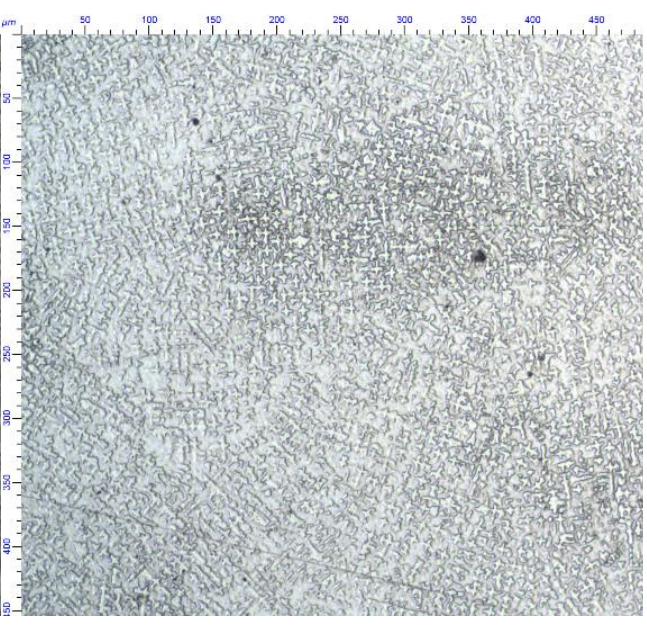

b)

Fig. 2. The structure of samples obtained by weld deposition with and without vibrations in the zone of crystallization.

In Fig. 2a, we can clearly see dendrites of the first, second and third kind, whereas, with using vibrational processing $(400 \mathrm{~Hz})$, in Fig. $2 \mathrm{~b}$, only dendrites of the first and the second kind can be seen. Their number is also significantly smaller than in the case of weld deposition without using vibration. Also, it can be added that, when using vibration, the average hardness of the material was $10 \%$ higher (Brinnell scale).

The above-listed measures can improve the efficiency of processing complexes for hybrid technologies.

The work for developing a hybrid complex was divided into 2 stages. During the first stage, only the module for additive build-up of articles was created. It consists of a source of laser radiation, a weld deposition head, a powder feeder and a robot-manipulator.

The weld deposition head is the main working organ of the DED installation combining several systems: a system for laser beam focusing, a cooling system, a material feeding system and control systems (sensors, cameras etc.).

The main purpose of the head is feeding powder to the melting zone. The most widely used variants of the system are as follows:

- lateral single-jet - the powder is fed from the side. As a result, the deposited bead is elongated. The process must be strictly vertical.

- multi-jet (usually, three or for jets) - feeding from several nozzles. It is a modification of the lateral feeding method that ensures symmetrical feeding of the powder relative to the direction of movement. This method of feeding is not sensitive to the movement direction relative to powder feeding and allows inclination of the head in a wide range, up to 45 degrees from the vertical. 
- coaxial - the powder is fed with a coaxial laser beam. It ensures the thinnest gas-powder stream, and, therefore, the deposited bead. It ensures the best material use factor. The process must be strictly vertical.

Therefore, the preferred tool is the multi-jet weld deposition head manufactured by the company Fraunhofer. It allows the processing angle up to 90 deg., the laser beam power up to $5 \mathrm{~kW}$, and the best factor of material use (up to $95 \%$ ).

In comparison with $\mathrm{CO}_{2}$-lasers, optic-fiber lasers have 2-3 times higher performance index (about 25-30\%) and require smaller operating costs. From this viewpoint, optic-fiber lasers are more cost-efficient, despite their higher price.

In Russia, industrial optic-fiber lasers are only manufactured by STA "IRE-Polus" (Friasino, Moscow district) that is a part of "IPG Photonics Corp." — an international scientific-manufacturing group of the Russian origin. The share of IPG is above $75 \%$ of the world amount of optic-fiber lasers production, with most types of optic-fiber lasers that are of the most relevance for industrial use, in particular, in the kilowatt power range, are only manufactured by IPG Photonics.

Due to the selection of the particular weld deposition head, an optic-fiber laser ЛС-3 was used - maximum power is $3 \mathrm{~kW}$, wavelength is $1070 \mathrm{~nm}$.

At the present moment, there are a lot of companies in the market that manufacture modules for feeding gas-powder mixture. They all are based on the same principle: the powder is transported by gas (Argon or Nitrogen depending on the weld deposition material). Powder feeding is controlled by a rotating dosing disc. With increasing rotation speed, the system receives a larger volume of powder. As a result, the powder feeder with two flasks was selected (manufactured by the company "Plaqart").

For the manipulator, the industrial robot Fanuc M20i was selected. Due to its loading capacity, the large number of degrees of freedom and accurate positioning. Fig. 3 shows an installation assembly with a protective cover.

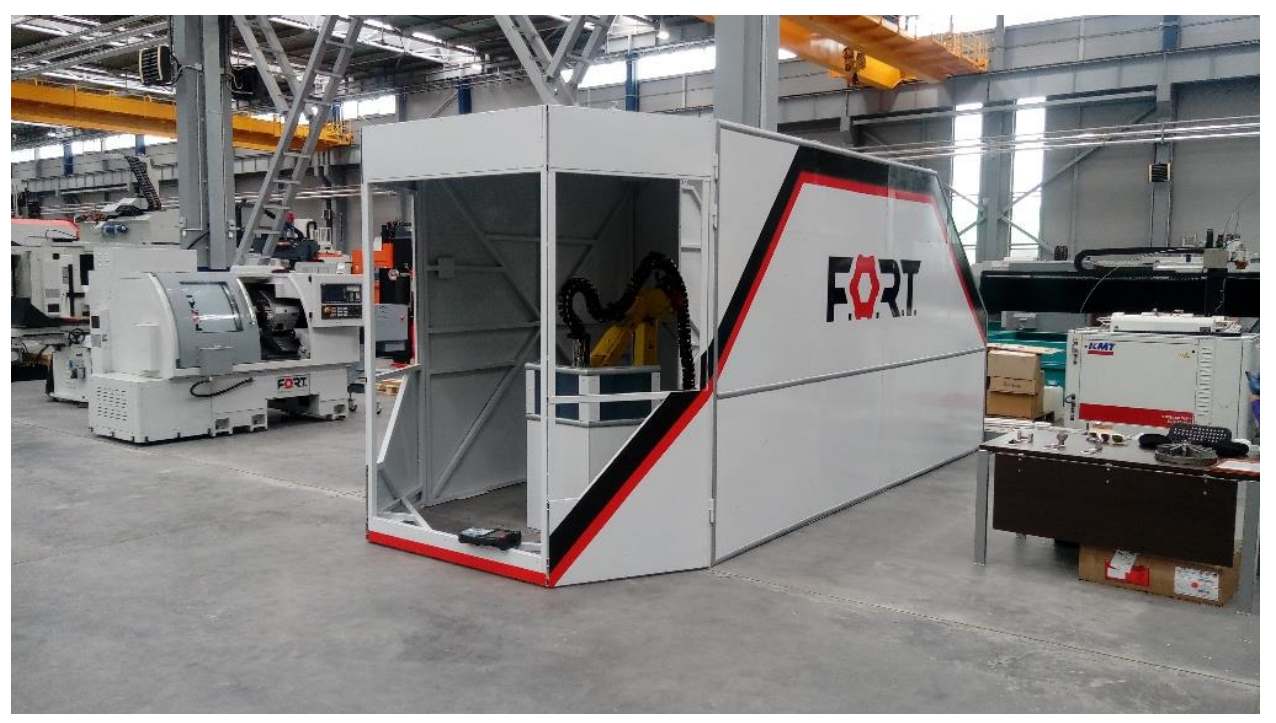

Fig. 3. A laser installation for powder weld deposition.

For creating a digital model and adjusting the technology, the CAM system "SprutCam" was used. Basing on the parameters of the process (track thickness and width, speed of movement, article geometry) this software develops strategies for the robot to move the weld deposition head (Fig. 4). 
The software makes it possible to:

- develop the strategy of additive manufacturing of the article;

- develop the strategy of repairs of the article;

- develop the strategy of coating application.

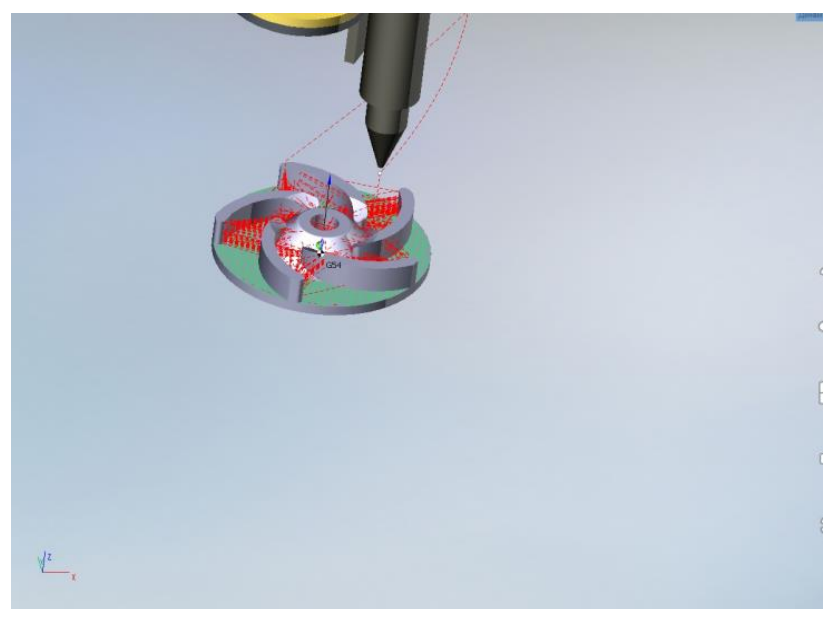

Fig. 4. Interface of the software complex "Sprut" for creating a digital model for manufacturing.

In the future, the software complex "Sprut" can also be used for a hybrid system.

Fig. 5 shows a variant of the structural scheme of the hybrid complex.
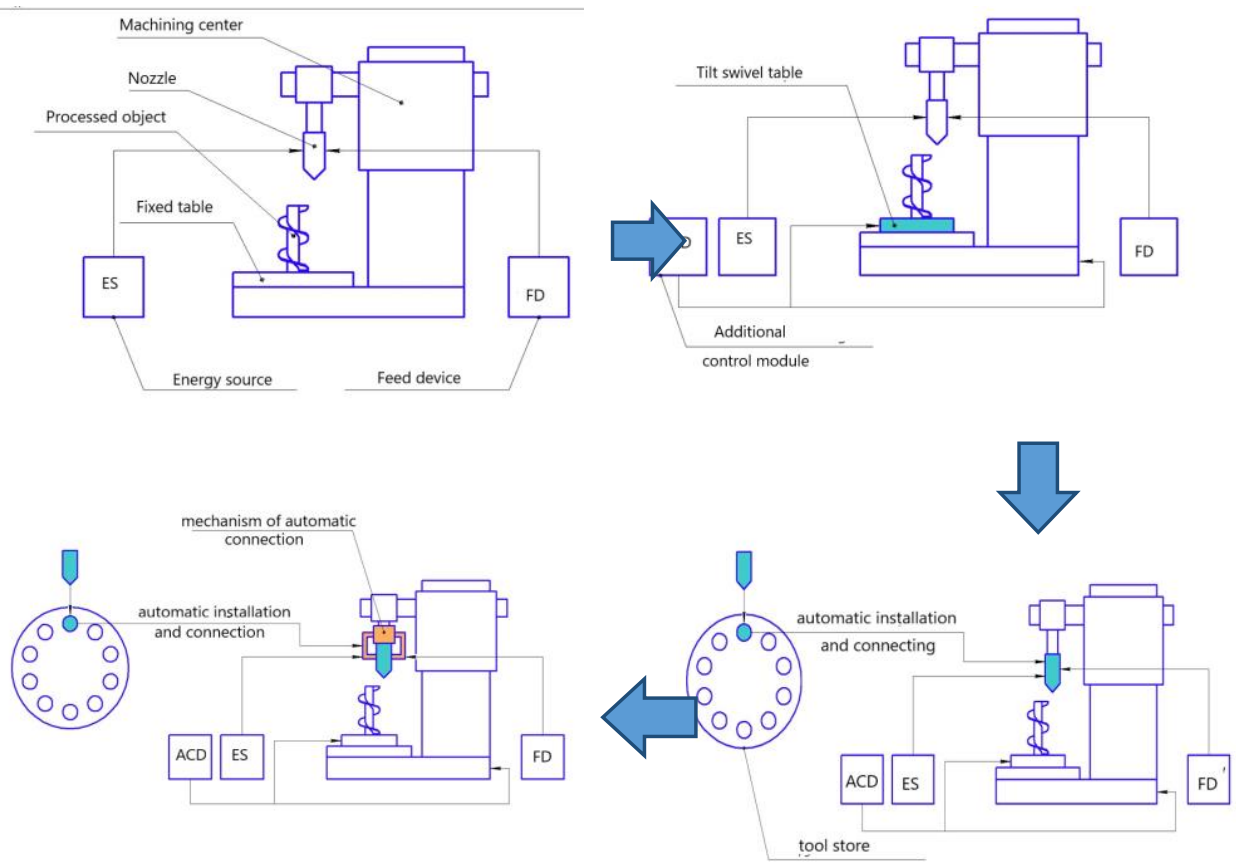

Fig. 5. The algorithm for creating a processing complex for using hybrid technologies

This algorithm is not final. Similarly to the module for gas-powder weld deposition, modifications are possible, in particular, modernization of the hybrid system. 


\section{Conclusion}

In this work, we analyzed the equipment for a laser installation for powder weld deposition. We presented the software to create control programs for this installation. We indicated the possible drawbacks regarding the hybrid technologies available in the world market. We presented a variant of the conceptual scheme for developing Russian equipment for using digitally-controlled hybrid technologies.

\section{References}

1. M. Zlenko, A. A. Popovich, I. N. Mutylina, Additive technologies in mechanical engineering. (Publishing house Polytechnic University, Saint Petersburg, 2013)

2. B. Mueller, Assembly Automation. 32(2) (2012)

3. Frazier W. E, Journal of Materials Engineering and Performance. 23(6) (2014)

4. Electronic resource DMG MORI [online], Available at: https://en.dmgmori.com/ (2018)

5. L. Qin, W. Wang, G. Yang. Applied Mechanics and Materials, 271-272 (2012)

6. F. Ning, W. Cong. Materials Letter, 179 (2016)

7. X. Chen, T. Sparks, J. Ruan, F. Liou, Advance Materials Research. 189-193 (2011) 